\title{
Experimental and Numerical Investigation of Tensile and Flexural Behavior of Nanoclay Wood-Plastic Composite
}

\author{
Mohammad E. Golmakani ${ }^{1}$, Tomasz Wiczenbach ${ }^{2, *} \mathbb{D}$, Mohammad Malikan ${ }^{2}{ }^{\mathbb{D}}$, Seyed M. Mahoori ${ }^{1}$ \\ and Victor A. Eremeyev 2,3 (D) \\ 1 Department of Mechanical Engineering, Mashhad Branch, Islamic Azad University, \\ Mashhad 9187144123, Iran; m.e.golmakani@mshdiau.ac.ir (M.E.G.); me.mahvari@gmail.com (S.M.M.) \\ 2 Department of Mechanics of Materials and Structures, Gdansk University of Technology, \\ 80-233 Gdansk, Poland; mohammad.malikan@pg.edu.pl (M.M.); victor.eremeev@pg.edu.pl (V.A.E.) \\ 3 Department of Civil and Environmental Engineering and Architecture, Università degli Studi di Cagliari, \\ Via Marengo, 2, 09123 Cagliari, Italy \\ * Correspondence: tomasz.wiczenbach@pg.edu.pl; Tel.: +48-58-348-61-49
}

Citation: Golmakani, M.E.; Wiczenbach, T.; Malikan, M.; Mahoori, S.M.; Eremeyev, V.A. Experimental and Numerical Investigation of Tensile and Flexural Behavior of Nanoclay Wood-Plastic Composite. Materials 2021, 14, 2773. https://doi.org/10.3390/ma14112773

Academic Editor: Rafael Luque

Received: 23 April 2021

Accepted: 21 May 2021

Published: 24 May 2021

Publisher's Note: MDPI stays neutral with regard to jurisdictional claims in published maps and institutional affiliations.

Copyright: (c) 2021 by the authors. Licensee MDPI, Basel, Switzerland. This article is an open access article distributed under the terms and conditions of the Creative Commons Attribution (CC BY) license (https:// creativecommons.org/licenses/by/ $4.0 /)$.

\begin{abstract}
In this study, the effect of wood powder and nanoclay particle content on composites' mechanical behavior made with polyethylene matrix has been investigated. The wood flour as a reinforcer made of wood powder was at levels of 30, 40, and $50 \mathrm{wt} . \%$, and additional reinforcement with nanoclay at $0,1,3$, and $5 \mathrm{wt} . \%$. Furthermore, to make a composite matrix, high-density polyethylene was used at levels of 70,60, and 50\% by weight. Wood-plastic composite (WPC) specimens were manufactured in injection molding. After preparing the specimens, tensile and bending tests were performed on samples. The mechanical properties such as tensile and flexural strength and flexural modulus were measured. Results showed that nanoclay particle content increases flexural modulus, flexural strength, modulus of elasticity, and tensile strength. The experimental test results show that Young's moduli increased with the volume of wood flour. The biggest modulus of elasticity was achieved in the samples having $50 \mathrm{wt} . \%$ of wood powder. Furthermore, the highest value of tensile strength was achieved at the level of $30 \mathrm{wt} . \%$. The highest flexural strength was for the sample containing 50\% wood powder by weight. Additionally, a numerical model was made utilizing the Abaqus software using the finite element method (FEM). Comparing the numerical and experimental results, it was found that they are compatible in the linear-elastic and plastic state of the material. There are no crucial differences between experiment and FEM.
\end{abstract}

Keywords: wood-plastic composite; nanoclay; polyethylene; wood powder; mechanical properties

\section{Introduction}

Wood-plastic composite (WPC) is a promising and sustainable green material with similar properties to wood but with better water resistance and characterized by satisfactory stability of properties in many environments [1,2]. In the WPCs, the filler comprises waste wood in various forms, such as chips, sawdust, shavings, splinters, or the most common, wood flour. Due to the unique combination of polymer and wood properties and their attractive appearance, WPCs have become an interesting alternative for both polymers and wood industry products [3]. Their main advantage is using the same processing tools as their natural counterpart, wood [4].

According to the thermoplastic matrix, these composites can be used where natural wood does not meet the conditions necessary for its operation due to its resistance to water and biological corrosion [5,6]. Simultaneously, using a thermoplastic matrix allows them to be processed with classical polymer processing methods, which has a beneficial effect on production. Polyethene (PE), polypropylene (PP), and polyvinyl chloride (PVC) are usually used as the WPC matrix. 
Another significant advantage of WPCs is that they have unique properties derived from combining the beneficial characteristics of wood and thermoplastic. Polymer composites filled with wood flour present favorable mechanical properties and higher stiffness compared to unfilled polymer materials [7]. Furthermore, compared with wood and woodbased materials, they are characterized by much lower water absorption and resistance to external (e.g., atmospheric) factors [8]. Moreover, applying waste wood materials as fillers for WPC is very favorable for ecological reasons. They are not a hazard to the natural environment during processing and recycling processes. Additionally, after proper modification, WPCs become partially biodegradable $[9,10]$.

Moreover, the improvement of WPCs' development can be achieved with nanoscience and nanotechnology. The use of nanosized fillers in WPC production can improve their mechanical and physical properties [11]. Depending on the expected properties, the types of nanofillers can be chosen. The most popular nanoclays are obtained from layered silicates. This nanosized filler usage can improve flexural and tensile strength and decrease water absorbance [12]. These properties can be significantly enhanced by increasing the interfacial area of polymer and wood flour. The particle size of nanoclays is less than 2 microns.

What is more, a small quantity of nanoclays can increase the mechanical properties of the composite. Nanoclays, with their high aspect ratio and nanometer size, provide increased particle-particle and polymer-particle interactions compared to traditional fillers [13]. Additionally, the addition of nanofiller in the composite decreases thickness swelling and water absorption.

Polymer nanocomposites provide additional properties with low filling (3-5 wt.\% on average, max. $10 \mathrm{wt} . \%)$. This allows maintaining all the advantages of the original composite simultaneously. The essential benefits of nanoparticles in WPC production are increased stiffness without loss of impact strength, dimensional stability, improvement of the barrier effect, and reduced surface defects of products [14].

Sharma et al. [15] conducted a polymer-based composite with glass fiber and nanoclay reinforcements. They found that by increasing the amount of nanoclay up to $3 \%$, tensile strength increased, and by adding nanoclay more than $3 \%$, the strength decreased.

Islam et al. [16] reinforced the epoxy matrix with carbon nanotubes and nanoclay. After preparing the samples, a bending test was performed. The results of this experiment showed that the flexural strength is improved by adding nanoparticles. According to the impact test, it could be concluded that the samples reinforced with nanoparticles can absorb more energy than the control samples.

In a study, Deepak et al. [17] investigated the effect of using coconut shell and nanoclay as a reinforcing material in polyester. The results show that by increasing nanoclay, tensile strength, impact energy, and compressive strength increase.

Zunjarrao et al. [18] investigated the effect of nano- and micro-sized aluminum particles as reinforcements in the epoxy matrix. Failure test for three different samples of pure epoxy, particle-reinforced epoxy 20-100 $\mu \mathrm{m}$, and epoxy reinforced with particles of 3-4.5 $\mu \mathrm{m}$ were conducted. Observations show that with the addition of particles to the epoxy, the toughness increases. The toughness of epoxy reinforced with particles of $20-100 \mu \mathrm{m}$ is higher than that of epoxy with particles of 3-4.5 $\mu \mathrm{m}$. Failure occurs at higher loads in both specimens, but this improvement is more significant for 3-4.5 $\mu \mathrm{m}$ particles than $20-100 \mu \mathrm{m}$.

In a study conducted by Srinivasa et al. [19], arka fruit peel was placed in the epoxy matrix as a reinforcing material. An impact test was performed on the specimens. Each sample was tested five times, and the average of the five tests was considered. The results of this experiment show that the strength of composites increases with increasing component volume.

Plastics have low strength due to their low Young's modulus, but their applications are very wide. The main advantages of plastic materials are their low weight and applicability for high humidity environment. On the other hand, wood powder as reinforcement 
is a relatively cheap material. Its use is very extensive, as shown in the cited articles. Creating a composite from these two materials gives an excellent application in various engineering fields. Unfortunately, like each of the composite materials, its physical and mechanical properties are varied in the context of the different content of individual materials. Additionally, one of the newest solutions to strengthen materials is nanoparticles, e.g., nanoclay. The additional reinforcement resulting from the different content of these molecules strengthens the final material to some point. Therefore, the main objective of this paper is to investigate the mechanical properties of WPC containing different amounts of wood powder and strengthened with nanoparticles. Additionally, numerical analysis was performed to evaluate the experimental results. What is more, the mechanical properties of WPC containing different amounts of wood powder are given. Moreover, this research could influence the design of WPC products, considering the increase of mechanical and physical properties.

\section{Materials and Methods}

\subsection{Materials}

In this research, the matrix material is heavy polyethylene prepared from Arak Petrochemical Trading Company (Tehran, Iran) with code 5218 and a melt flow index of $18 \mathrm{~g} / 10$ $\mathrm{min}$, the specifications of which are given in Table 1.

Table 1. Specifications of polyethylene.

\begin{tabular}{ccc}
\hline $\begin{array}{c}\text { Melt Flow Index after } \\
\text { Recycling }(\mathrm{g} / \mathbf{1 0} \text { min })\end{array}$ & Melt Flow Index (g/10 min) & Density $\left(\mathrm{gr} / \mathrm{cm}^{\mathbf{3}}\right)$ \\
\hline 35.04 & 18 & 0.956 \\
\hline
\end{tabular}

The nanoclay used for the preparation of the specimens was prepared by SigmaAldrich company (Munich, Germany). The characteristics of the nanoclay are summarized in Table 2. Narad wood flour was used as a wood powder in the polymer matrix. Kian Choob Company (Tehran, Iran) prepared the wood flour. The wood flour was classified using a vibrating sieve to uniform the particle size and reach the desired size. Firwood flour, which passed through 60 mesh, and the rest on a sieve with 80 mesh, was considered flour. The samples were then placed in an oven at $100{ }^{\circ} \mathrm{C}$ for $24 \mathrm{~h}$ to dry.

Table 2. Specifications of polyethylene bonded with maleic anhydride.

\begin{tabular}{ll}
\hline Properties & K10 \\
\hline Organic Modifier & MT2EtOH \\
\hline Base & Montmorillonite \\
\hline Density & $300-370 \mathrm{~kg} / \mathrm{m}^{3}$ \\
\hline Anion & Chloride \\
\hline Modifier Concentration & $48 \mathrm{meq} / 100 \mathrm{~g}$ \\
\hline Moisture & $1-2 \%$ \\
\hline Weight Loss on Ignition & $30 \%$ \\
\hline According to Producer Information & \\
\hline
\end{tabular}
Table 3.

The coupling agent maleic anhydride was used. Its specifications are presented in 
Table 3. Specifications of polyethylene bonded with maleic anhydride.

\begin{tabular}{ccc}
\hline $\begin{array}{c}\text { The Amount of Anhydride } \\
\text { Bonded (wt.\%) }\end{array}$ & Melt Flow Index (g/10 min) & Density (gr/cm $\left.\mathbf{c}^{\mathbf{3}}\right)$ \\
\hline $1 \%$ & 7 & 0.965 \\
\hline
\end{tabular}

\subsection{Preparation of Wood-Plastic Composite}

The mixing process was performed using the internal mixer HBI System 90 made by the American company Haake Buchler (New Jersey, NJ, USA). A mixing temperature of $170{ }^{\circ} \mathrm{C}$ and mixing speed of $60 \mathrm{RPM}$ were used. The total mixing time until reaching constant torque was $10 \mathrm{~min}$. First, polyethylene was poured into the device's housing, and after melting for $2 \mathrm{~min}$ and reaching constant torque, maleic and nanoclay were added. After $5 \mathrm{~min}$, flour was added. The wood was poured into the chamber, and the mixing operation was carried out continuously until a constant torque was reached.

After cooling and hardening, the material was granulated using the Wieser WG-Ls 200 semi-industrial shredder (Wieser Company, Hamburg, Germany). The compounds of each specimen are shown in Table 4.

Table 4. The number of compounds in each specimen.

\begin{tabular}{ccccc}
\hline Specimen & PE (\%) & MA (\%) & Nanoclay (\%) & Wood Flour (\%) \\
\hline 1 & $70 \%$ & $3 \%$ & $0 \%$ & $30 \%$ \\
2 & $70 \%$ & $3 \%$ & $1 \%$ & $30 \%$ \\
3 & $70 \%$ & $3 \%$ & $3 \%$ & $30 \%$ \\
4 & $70 \%$ & $3 \%$ & $5 \%$ & $30 \%$ \\
5 & $60 \%$ & $3 \%$ & $0 \%$ & $40 \%$ \\
6 & $60 \%$ & $3 \%$ & $1 \%$ & $40 \%$ \\
7 & $60 \%$ & $3 \%$ & $5 \%$ & $40 \%$ \\
8 & $60 \%$ & $3 \%$ & $0 \%$ & $50 \%$ \\
9 & $50 \%$ & $3 \%$ & $1 \%$ & $50 \%$ \\
11 & $50 \%$ & $3 \%$ & $3 \%$ & $50 \%$ \\
12 & $50 \%$ & $3 \%$ & $5 \%$ & $50 \%$ \\
\hline
\end{tabular}

The granules were then transferred to an injection molding machine to make standard test specimens. For this purpose, a semi-industrial injection machine made by Imen Machine Company (Tehran, Iran) of Tehran was used. The injection cylinder temperature in each region was 155,165 and $175^{\circ} \mathrm{C}$. The injection pressure was $100 \mathrm{MPa}$ and lasted for less than $75 \mathrm{~s}$. The mold was cooled with cold water, and the samples were taken out of the mold after $2 \mathrm{~min}$. The injection mold was designed so that the specimen, according to ASTM D638-02A [20] and ASTM D790-02 [21] standards, for tensile, bending, and impact tests were obtained. Figure 1 shows a sample taken out of the mold. Figure la presents the specimen for the tensile test, and Figure $1 \mathrm{~b}$ shows the bending test sample. Additionally, Figure $2 \mathrm{a}, \mathrm{b}$ show the dimensions of samples for the tensile and bending test, respectively.

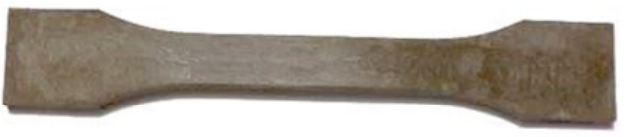

(a)

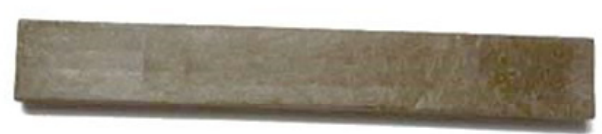

(b)

Figure 1. Specimens for: (a) tensile test; (b) bending test. 


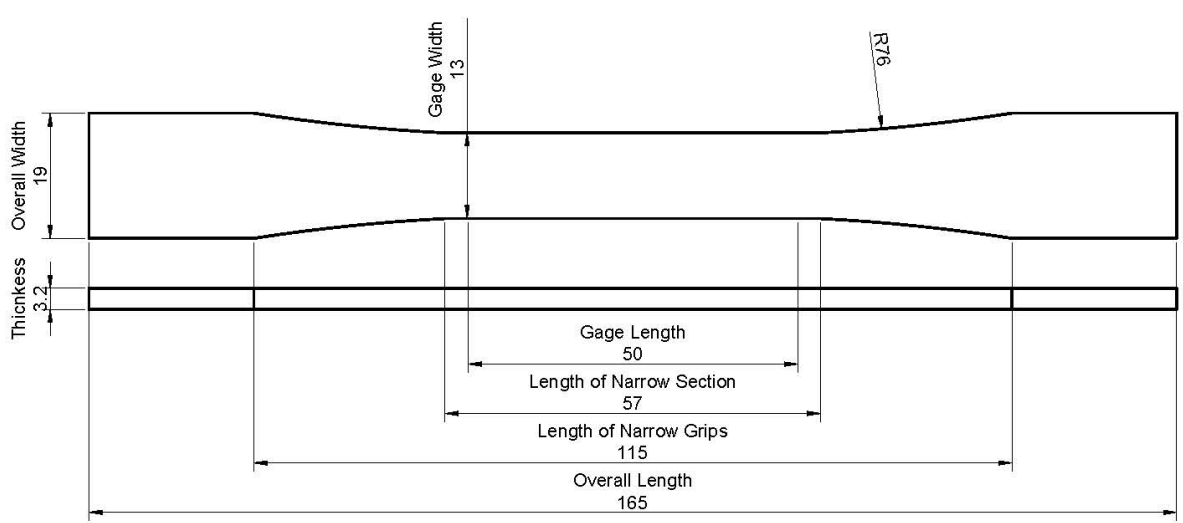

(a)

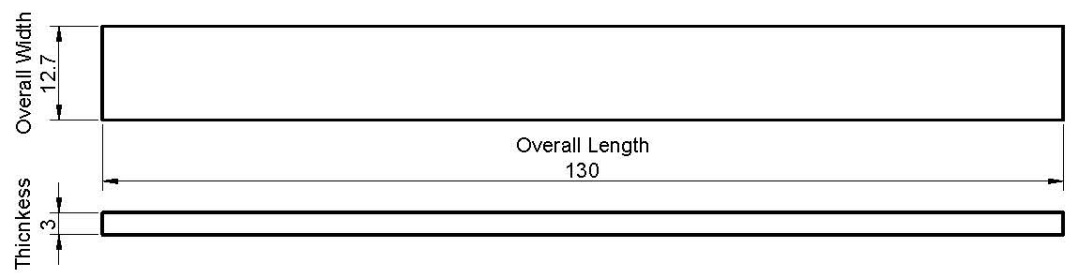

(b)

Figure 2. Dimension of samples [mm] for (a) tensile test; (b) bending test.

\subsection{Mechanical Testing}

To evaluate the mechanical properties of wood-plastic composite, the tensile and bending test, according to ASTM D638-02A and ASTM D790-02, respectively, were performed. The experimental tests of specimens were done on the testing device Instron 4486 at room temperature. All tensile and bending tests were conducted applying a $500 \mathrm{~N}$ load cell. What is more, the crosshead speed moved at $2 \mathrm{~mm} / \mathrm{min}$. All performed mechanical testing of each sample composition was performed no fewer than five times, and the mean values were computed and taken into consideration. According to obtained force-displacement curves, the calculations were performed to obtain tensile strength, flexural strength, and Young's moduli. Additionally, to calculate the Poisson's ratios, the two-way TML strain gauge was installed on the test specimens. Measurement with this device allowed to the calculation of the Poisson's ratios.

\subsection{Statistical Analysis}

In this study, SPSS 24 software (24.0, IBM Corp., Armonk, NY, USA) was used. Statistical analysis of data was performed using variance analysis and comparison of mean values using Duncan's test. The variable factor's effect on the studied properties was investigated at a $95 \%$ confidence level (5\% significance level).

\subsection{Numerical Analysis}

\subsubsection{Tensile Test Simulation}

The WPC specimen was modeled following the shape and dimensions of the ASTM D638-02A standard in Abaqus software version 6.14.1 (Dassault Systemes, ABAQUS Inc., Waltham, MA, USA).

The properties of two-phase elastic and plastic materials for the wood-plastic composite were considered. In the linear-elastic region, the material was deemed to be isotropic. The Young's modulus and Poisson's coefficient were entered for each sample's according to Table 5. Then plastic behavior was modeled. First, the yield stress and plastic strain zero value were entered as the plastic strain corresponding to the yield stress to define the plastic region's material properties. Then, in the next row, the stress greater than the yield stress and the corresponding plastic strain was entered. 
Table 5. Material properties for each specimen.

\begin{tabular}{cccccc}
\hline Specimen & $\left.\boldsymbol{\sigma}_{\mathbf{y}} \mathbf{( M P a}\right)$ & $\boldsymbol{\sigma}_{\text {num }}(\mathbf{M P a})$ & $\boldsymbol{\varepsilon}_{\mathbf{p}} \mathbf{( - )}$ & $\mathbf{E}(\mathbf{M P a})$ & $\boldsymbol{v}(-)$ \\
\hline 1 & 14.61 & 19.41 & 0.0243 & 2244.67 & 0.3422 \\
2 & 14.68 & 19.11 & 0.0253 & 2314.00 & 0.3988 \\
3 & 14.20 & 16.80 & 0.0165 & 2325.25 & 0.4435 \\
4 & 13.86 & 18.98 & 0.0157 & 2355.75 & 0.4800 \\
5 & 13.83 & 18.54 & 0.0088 & 3498.75 & 0.3520 \\
6 & 13.70 & 18.31 & 0.0081 & 3307.25 & 0.4052 \\
7 & 14.10 & 20.34 & 0.0111 & 4130.33 & 0.4549 \\
8 & 14.20 & 20.52 & 0.0119 & 4184.00 & 0.4883 \\
9 & 14.75 & 17.12 & 0.0037 & 4756.50 & 0.3750 \\
10 & 15.88 & 20.52 & 0.0053 & 4899.67 & 0.4285 \\
11 & 12.80 & 18.14 & 0.0047 & 4951.25 & 0.4684 \\
12 & 13.12 & 19.59 & 0.0045 & 5426.25 & 0.4955 \\
\hline
\end{tabular}

The boundary conditions of one side of the specimen at the device's fixed grip was motionless, and the other side could move in a neutral axis direction. Mesh size was selected as $1 \mathrm{~mm}$. The model was prepared only for half of the specimen because of symmetry. Finally, the sample was aligned with the hexagonal elements in a regular and uniform form. Then, the analysis was performed with Abaqus software.

Figure 3 shows the meshed specimen for the numerical tensile test.

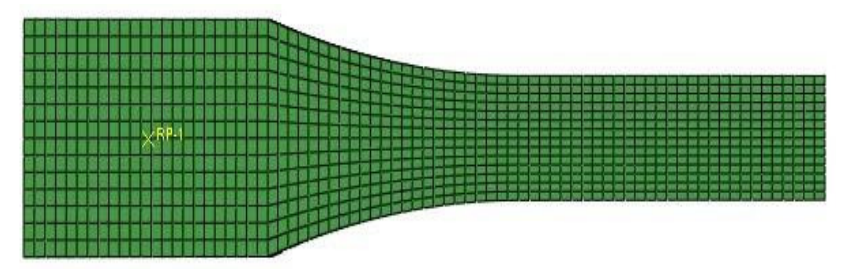

Figure 3. Specimen model for the numerical tensile test.

\subsubsection{Bending Test Simulation}

The WPC specimen was modeled following the shape and dimensions of ASTM D790-02 standard in Abaqus software version 6.14.1. The mechanical properties of each specimen are considered, according to Table 5 . One of the grips was deemed immobile for the boundary conditions, and the second grip was movable only vertically. Then, two supports and a load-applying device, which are cylindrical, were modeled. The contact of the upper grip with the sample surface was defined in the interaction module with the surface-to-surface mode. Then, using a rigid body constraint, the lower supporting grips and the upper movable grip were modeled as rigid, and their movement was limited to the movement of a point. In the loading module and in the boundary condition section, the lower supporting grips, whose movement was limited to one point, were considered immobile. The numerical value of the upper movable grip displacement was entered. The amount of movable grip displacement is obtained from the experimental test. The mesh size of $1 \mathrm{~mm}$ was finally selected. The hexagonal elements in regular and uniformed form were assigned.

Figure 4 shows a modeled specimen for a bending test. 


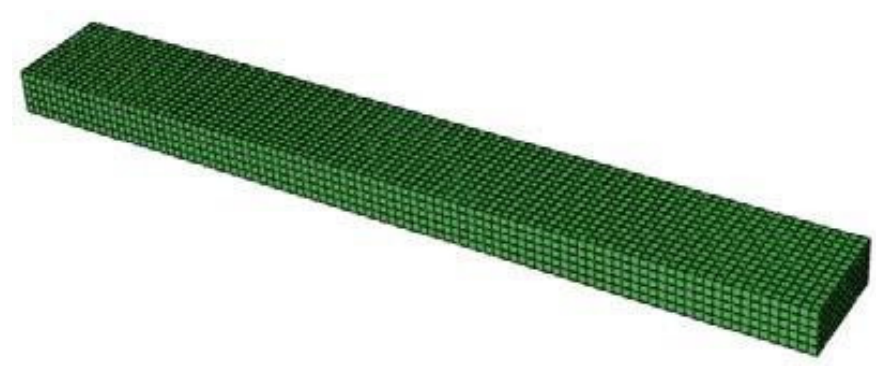

Figure 4. Model of the specimen for the numerical bending test.

\section{Results}

\subsection{Experimental Analysis}

Stress-strain curves are generally obtained through tensile tests, which are limited by the phenomenon of choking. Engineering stress-strain curves are converted to real stressstrain curves using direct relationships. The stress and strain values obtained from the tensile test were converted to real stress and strain values using the following formula. The amount of stress obtained from the tensile test using Equation (1) and the strain obtained from the tensile test using Equation (2) were converted into real stress and strain values. What is more, the amount of plastic strain was obtained using Equation (3).

$$
\begin{gathered}
\sigma_{\text {True }}=\sigma_{\text {Num }}\left(1+\varepsilon_{\text {Num }}\right), \\
\varepsilon_{\text {True }}=\ln \left(1+\varepsilon_{\text {Num }}\right), \\
\varepsilon_{P}=\varepsilon_{\text {True }}-\frac{\sigma_{\text {True }}}{E},
\end{gathered}
$$

where $\sigma_{\text {True }}$ is the real stress, $\varepsilon_{\text {True }}$ is the real strain, $\varepsilon_{\mathrm{Num}}$, is the engineering strain (from the tensile test), and $\varepsilon_{P}$ is the plastic strain.

The values of Young's moduli, Poisson's ratio, stress and strain are taken from the experimental tensile test and are shown in Table 5.

The addition of nanoclay to the samples showed that the modulus of elasticity in all three levels of $30 \%, 40 \%$ and $50 \%$ wood, with 5\% nanoclay to the samples compared to other values, had the highest value. Table 6 shows the modulus changes corresponding to the changes in wood powder and nanoclay. Examining the variance analysis in the modulus of elasticity showed that changes in nanoclay at levels of $0 \%, 1 \%, 3 \%$ and $5 \%$ had a significant effect on the statistical confidence level 95\%. According to Duncan grouping, two different groups were examined. The first one is with $0 \%$ and $1 \%$ nanoclay and the second with $3 \%$ and $5 \%$ values. The highest modulus was obtained in the second group, according to this test.

Table 6. The modulus of elasticity according to the changes in wood flour and nanoclay.

\begin{tabular}{cccc}
\hline Specimen & Wood Flour (\%) & Nanoclay (\%) & Young's Moduli (MPa) \\
\hline 1 & $30 \%$ & $0 \%$ & 2244.67 \\
2 & $30 \%$ & $1 \%$ & 2314.00 \\
3 & $30 \%$ & $3 \%$ & 2325.25 \\
4 & $30 \%$ & $5 \%$ & 2355.75 \\
5 & $40 \%$ & $0 \%$ & 3498.75 \\
6 & $40 \%$ & $1 \%$ & 3304.25 \\
7 & $40 \%$ & $3 \%$ & 4130.33 \\
8 & $40 \%$ & $5 \%$ & 4184.00 \\
9 & $50 \%$ & $0 \%$ & 4756.50 \\
10 & $50 \%$ & $1 \%$ & 4899.67 \\
11 & $50 \%$ & $3 \%$ & 4951.25 \\
12 & $50 \%$ & $5 \%$ & 5426.25 \\
\hline
\end{tabular}


The sample with $1 \%$ nanoclay had the highest resistance. Examining the tensile strength variance showed that changes in the amount of nanoclay at levels of $0 \%, 1 \%$, $3 \%$ and $5 \%$ have no significant effect. Table 7 presents the results of nanoclay on tensile strength.

Table 7. Impact of nanoclay on tensile strength.

\begin{tabular}{cccc}
\hline Specimen & Wood Flour (\%) & Nanoclay (\%) & Tensile Strength (MPa) \\
\hline 1 & $30 \%$ & $0 \%$ & 19.41 \\
2 & $30 \%$ & $1 \%$ & 19.11 \\
3 & $30 \%$ & $3 \%$ & 16.80 \\
4 & $30 \%$ & $5 \%$ & 18.98 \\
5 & $40 \%$ & $0 \%$ & 18.54 \\
6 & $40 \%$ & $1 \%$ & 18.31 \\
7 & $40 \%$ & $3 \%$ & 20.34 \\
8 & $40 \%$ & $5 \%$ & 20.52 \\
9 & $50 \%$ & $0 \%$ & 17.12 \\
10 & $50 \%$ & $1 \%$ & 20.52 \\
11 & $50 \%$ & $3 \%$ & 18.14 \\
12 & $50 \%$ & $5 \%$ & 19.59 \\
\hline
\end{tabular}

The effect of adding nanoclay to the samples showed that at the level of $30 \%$ and $40 \%$ wood flour, the specimen containing $3 \%$ nanoclay had the highest flexural modulus. Still, at the $50 \%$ wood flour level, the sample containing $1 \%$ nanoclay had the highest flexural modulus. Table 8 shows the amount of nanoclay impact on the flexural modulus.

Table 8. The flexural modulus according to the amount of nanoclay.

\begin{tabular}{cccc}
\hline Specimen & Wood Flour (\%) & Nanoclay (\%) & Flexural Modulus (MPa) \\
\hline 1 & $30 \%$ & $0 \%$ & 2481.00 \\
2 & $30 \%$ & $1 \%$ & 2372.67 \\
3 & $30 \%$ & $3 \%$ & 2610.67 \\
4 & $30 \%$ & $5 \%$ & 2602.33 \\
5 & $40 \%$ & $0 \%$ & 2778.67 \\
6 & $40 \%$ & $1 \%$ & 2946.00 \\
7 & $40 \%$ & $3 \%$ & 3320.67 \\
8 & $40 \%$ & $5 \%$ & 3210.33 \\
9 & $50 \%$ & $0 \%$ & 3565.33 \\
10 & $50 \%$ & $1 \%$ & 4186.67 \\
11 & $50 \%$ & $3 \%$ & 3452.67 \\
12 & $50 \%$ & $5 \%$ & 3905.67 \\
\hline
\end{tabular}

Table 9 shows the amount of nanoclay impact on flexural strength. Examining the variance analysis in the flexural modulus showed that changes in the amount of nanoclay at levels of $0 \%, 1 \%, 3 \%$ and $5 \%$ significantly affected the statistical confidence level of $95 \%$. Duncan grouping for the impact of nanoclay on the flexural strength divided the four specimens into two separate groups, so specimens of $0 \%$ and $3 \%$ are in the first group with the lowest flexural strength. Values of $1 \%$ and $5 \%$ nanoclay are in the second group with the highest flexural strength value. The effect of adding nanoclay to the samples showed that at the level of $30 \%$ wood flour, the model containing 3\% nanoclay had the highest flexural strength. Still, at the levels of $40 \%$ and $50 \%$ wood flour, the specimen with $5 \%$ nanoclay has the highest flexural strength. 
Table 9. The flexural strength according to the amount of nanoclay.

\begin{tabular}{cccc}
\hline Specimen & Wood Flour (\%) & Nanoclay (\%) & Flexural Strength (MPa) \\
\hline 1 & $30 \%$ & $0 \%$ & 43.84 \\
2 & $30 \%$ & $1 \%$ & 41.48 \\
3 & $30 \%$ & $3 \%$ & 46.17 \\
4 & $30 \%$ & $5 \%$ & 45.72 \\
5 & $40 \%$ & $0 \%$ & 40.78 \\
6 & $40 \%$ & $1 \%$ & 44.75 \\
7 & $40 \%$ & $3 \%$ & 46.84 \\
8 & $40 \%$ & $5 \%$ & 47.18 \\
9 & $50 \%$ & $0 \%$ & 45.87 \\
10 & $50 \%$ & $1 \%$ & 48.41 \\
11 & $50 \%$ & $3 \%$ & 46.84 \\
12 & $50 \%$ & $5 \%$ & 50.82 \\
\hline
\end{tabular}

Figure 5 shows the modulus changes based on the amount of wood powder for the samples containing $0 \%$ nanoparticles. Examination of the tensile test results shows that in the sample containing $50 \%$ wood particles, the modulus of elasticity is $4756.50 \mathrm{MPa}$, the highest obtained elastic modulus. The specimens containing $30 \%$ and $40 \%$ wood particles had Young's moduli which reached 2244.67 and $3498.75 \mathrm{MPa}$, respectively. As it can be seen, by having $50 \%$ wood powder compared with $30 \%$ wood powder content, Young's moduli doubled its value.

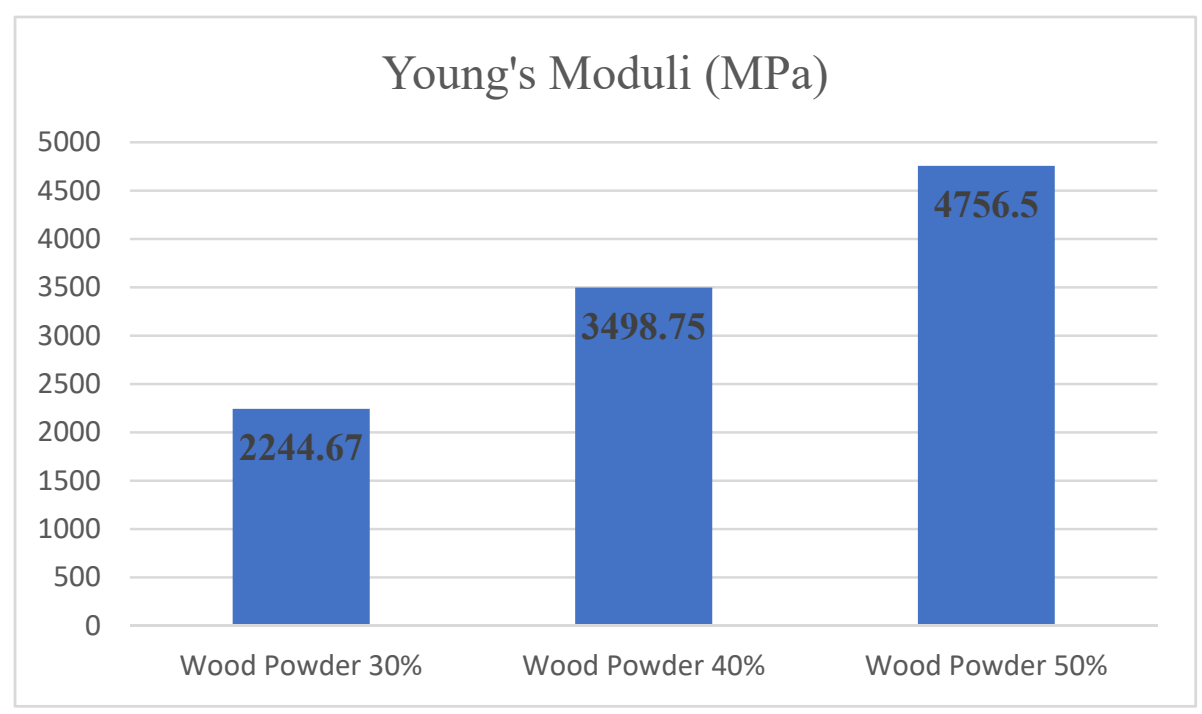

Figure 5. The Young's moduli according to the amount of wood powder and $0 \%$ nanoclay addition.

Figure 6 presents the tensile strength changes following the amount of wood powder for the specimens with $0 \%$ nanoclay. The tensile test results have shown that in the sample containing $30 \%$ wood particles, the tensile strength was equal to $19.40 \mathrm{MPa}$. By changing the amount of wood particles to 40 and $50 \%$, the value of tensile strength reached 18.54 and 17.12 MPa, respectively. According to the tensile test values, wood particles in all three levels have reduced the tensile strength. 


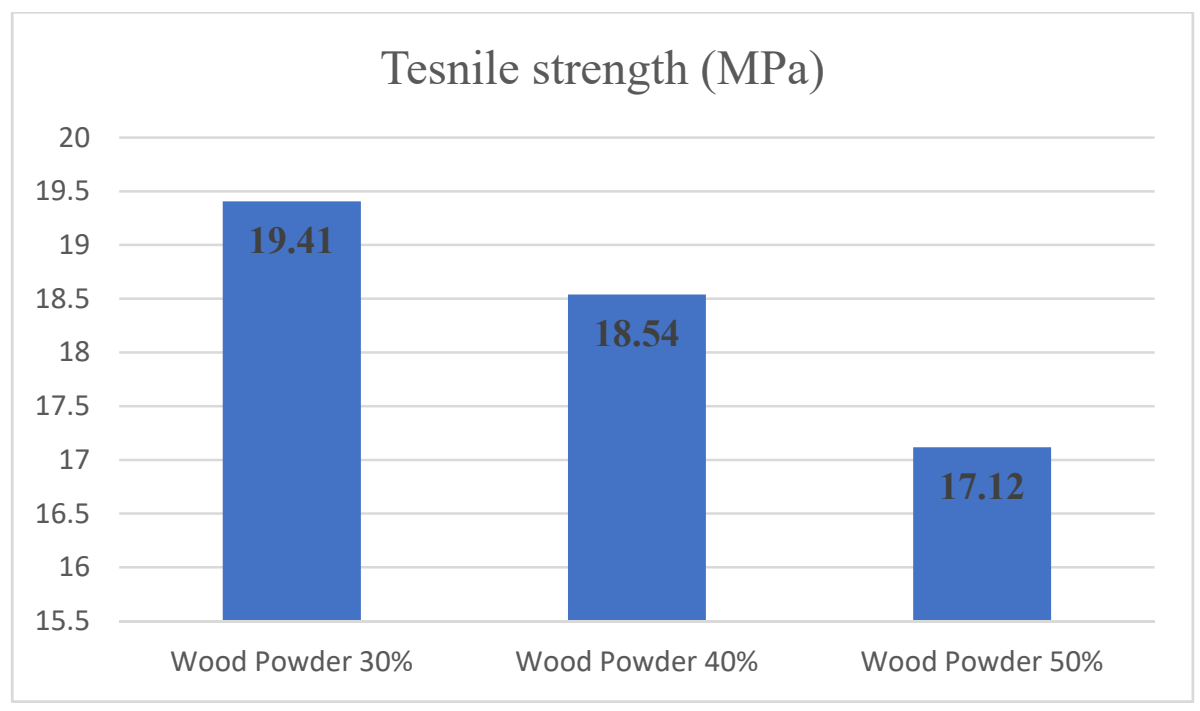

Figure 6. Tensile strength comparison according to a different amount of wood powder and $0 \%$ nanoclay.

Figure 7 shows the changes in the modulus of elasticity relative to the amount of wood flour. Examining the bending test results shows that the addition of wood particles has increased the flexural modulus in all three levels. Examining the flexural modulus variance analysis showed that changes in the amount of wood at levels of $30 \%, 40 \%$ and $50 \%$ significantly affected the statistical confidence level of $95 \%$. Duncan grouping also placed each level of wood values in a separate group to impact the amount of wood on flexural modulus. Hence, samples with $50 \%$ wood powder had the highest value of the flexural modulus.

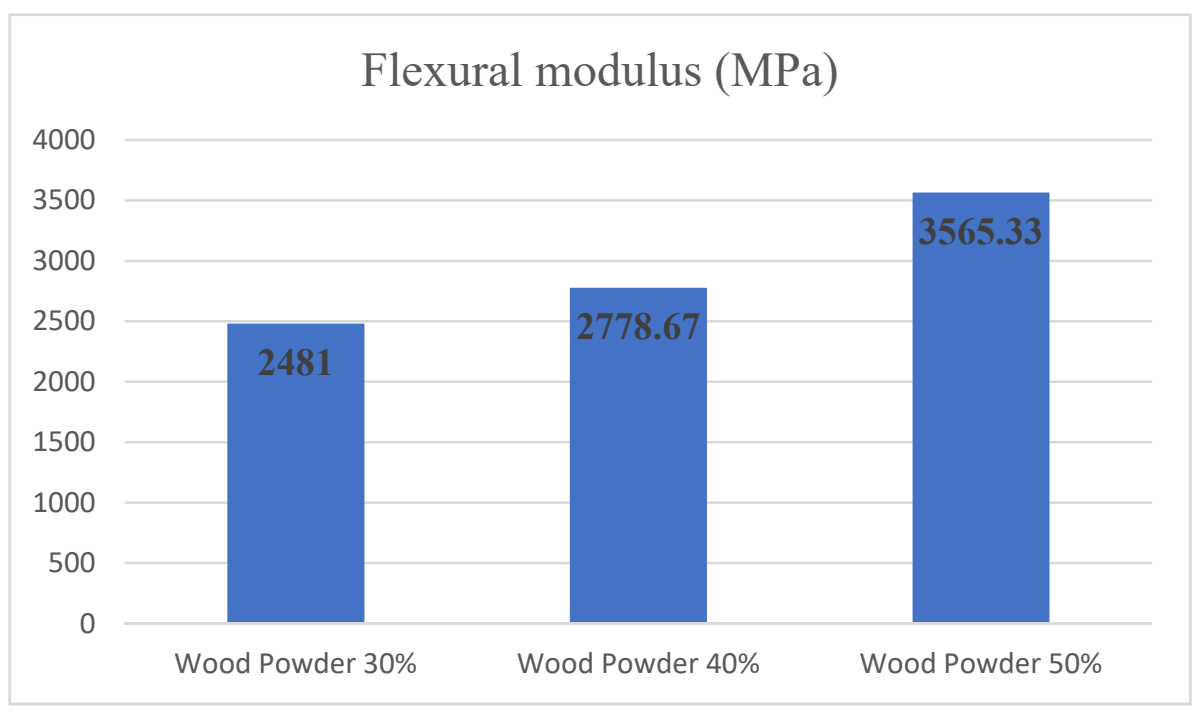

Figure 7. Flexural modulus comparison according to a different amount of wood powder and $0 \%$ nanoclay.

Figure 8 shows the changes in flexural strength relative to changes in the amount of wood flour. Examining the variance analysis in flexural strength showed that changes in the amount of wood at levels of 30\%, $40 \%$ and $50 \%$ significantly affected the level of statistical confidence of $95 \%$. Duncan grouping also divided the three levels of wood flour into two separate groups to assess the wood particles' impact on flexural strength. The specimens containing $30 \%$ and $40 \%$ by weight of wood particles are in the first group with 
the least amount of flexural strength, and the $50 \%$ by weight wood particles are in the second group with the highest amount of flexural strength.

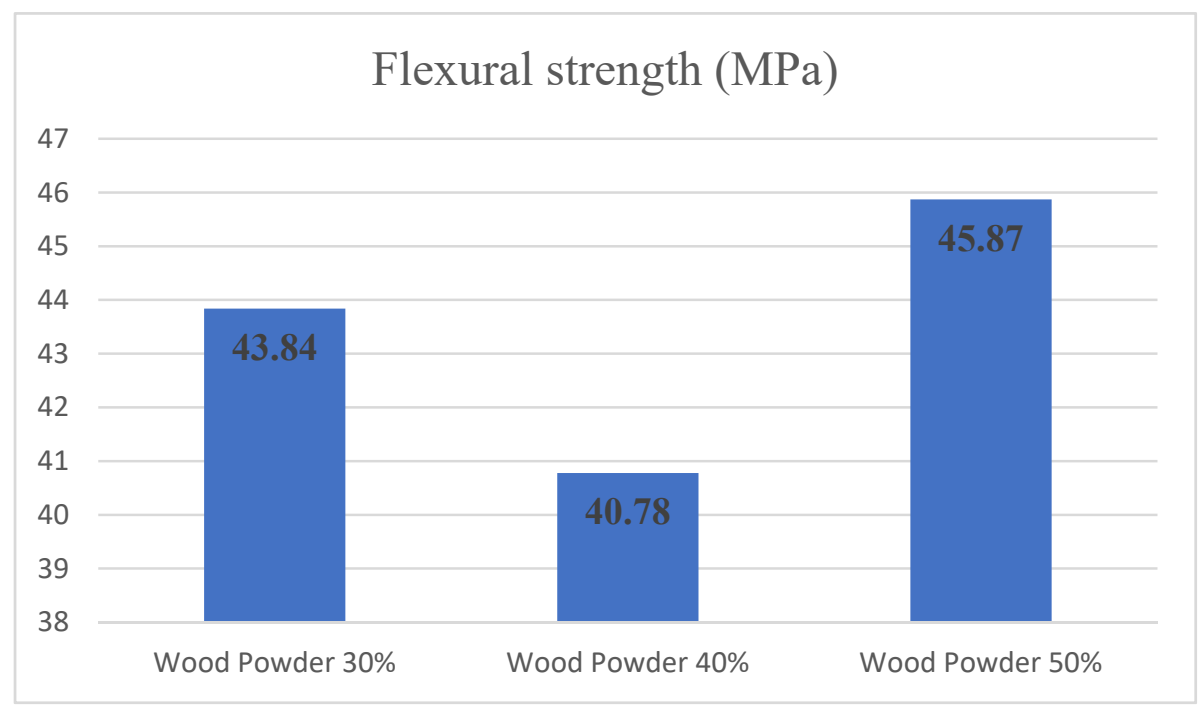

Figure 8. Flexural strength comparison according to a different amount of wood powder and $0 \%$ nanoclay.

\subsection{Numerical Analysis}

The failure tensile and bending force values for both the laboratory and numerical test are shown in Tables 10 and 11 with the percentage difference, respectively. As shown in the table, there is a difference between the experimental and the numerical results.

Table 10. Comparison of failure force obtained in the experimental and numerical tensile test.

\begin{tabular}{cccccc}
\hline Specimen & $\begin{array}{c}\text { Wood Flour } \\
\mathbf{( \% )}\end{array}$ & $\begin{array}{c}\text { Nanoclay } \\
\mathbf{( \% )}\end{array}$ & $\begin{array}{c}\text { Experimental } \\
\mathbf{( k N )}\end{array}$ & $\begin{array}{c}\text { Numerical } \\
\mathbf{( k N )}\end{array}$ & $\begin{array}{c}\text { Difference } \\
(\mathbf{\%})\end{array}$ \\
\hline 1 & $30 \%$ & $0 \%$ & 0.7762 & 0.8523 & $9.80 \%$ \\
2 & $30 \%$ & $1 \%$ & 0.7644 & 0.7979 & $4.30 \%$ \\
3 & $30 \%$ & $3 \%$ & 0.7181 & 0.7799 & $8.60 \%$ \\
4 & $30 \%$ & $5 \%$ & 0.7751 & 0.7717 & $0.40 \%$ \\
5 & $40 \%$ & $0 \%$ & 0.7385 & 0.8093 & $9.60 \%$ \\
6 & $40 \%$ & $1 \%$ & 0.7239 & 0.7887 & $8.90 \%$ \\
7 & $40 \%$ & $3 \%$ & 0.8136 & 0.8651 & $6.30 \%$ \\
8 & $40 \%$ & $5 \%$ & 0.8155 & 0.8675 & $6.40 \%$ \\
9 & $50 \%$ & $0 \%$ & 0.6593 & 0.7630 & $15.7 \%$ \\
11 & $50 \%$ & $1 \%$ & 0.8208 & 0.8504 & $3.60 \%$ \\
12 & $50 \%$ & $3 \%$ & 0.6782 & 0.7075 & $4.30 \%$ \\
\end{tabular}


Table 11. Comparison of the failure force in the experimental and numerical bending test.

\begin{tabular}{cccccc}
\hline Specimen & $\begin{array}{c}\text { Wood Flour } \\
\mathbf{( \% )}\end{array}$ & $\begin{array}{c}\text { Nanoclay } \\
\mathbf{( \% )}\end{array}$ & $\begin{array}{c}\text { Experimental } \\
(\mathbf{k N})\end{array}$ & $\begin{array}{c}\text { Numerical } \\
\mathbf{( k N )}\end{array}$ & $\begin{array}{c}\text { Difference } \\
\mathbf{( \% )}\end{array}$ \\
\hline 1 & $30 \%$ & $0 \%$ & 0.1054 & 0.0941 & $12.01 \%$ \\
2 & $30 \%$ & $1 \%$ & 0.1022 & 0.0882 & $15.87 \%$ \\
3 & $30 \%$ & $3 \%$ & 0.1069 & 0.0867 & $23.30 \%$ \\
4 & $30 \%$ & $5 \%$ & 0.1078 & 0.0839 & $28.49 \%$ \\
5 & $40 \%$ & $0 \%$ & 0.1002 & 0.0879 & $13.99 \%$ \\
6 & $40 \%$ & $1 \%$ & 0.1045 & 0.0885 & $18.08 \%$ \\
7 & $40 \%$ & $3 \%$ & 0.1116 & 0.0952 & $17.23 \%$ \\
8 & $40 \%$ & $5 \%$ & 0.1143 & 0.0949 & $20.44 \%$ \\
9 & $50 \%$ & $0 \%$ & 0.1129 & 0.0878 & $28.59 \%$ \\
10 & $50 \%$ & $1 \%$ & 0.1124 & 0.0877 & $28.16 \%$ \\
11 & $50 \%$ & $3 \%$ & 0.1155 & 0.0885 & $30.51 \%$ \\
12 & $50 \%$ & $5 \%$ & 0.1196 & 0.0958 & $24.84 \%$ \\
\hline
\end{tabular}

\section{Discussion}

The Young's moduli increase in nanofiller composites is directly related to the average length of clay particles and their dimensional ratio. Various structural factors such as volume ratio, nanoclay aspect ratio, particle spacing, and the amount of nanofiller particle cracking have a significant effect on the mechanical properties of clay-polymer composites. Additionally, the difference between the degree of swelling of the layers and the layer structure formation strongly affects the nanoclay composite's elasticity modulus. Besides, the percentage of nanofiller in composites plays a significant role, usually increasing the mechanical properties with the percentage of nanoclay [22]. However, after a specific limit, the increasing trend of properties stops or even decreases with the increment of the nanofiller particles [23].

Increasing the nanoclay, interlayer, and layer morphology in the nanofiller composite, due to the interfacial effect of organic chains and nanoclay particles and the orientation of layered silicate particles, increases the strength of the nanofiller composite. Additionally, the heterogeneity and high surface-to-volume ratio of nanoclay with organic matter contribute to the high-reinforcing capacity of nanofiller particles. It is done so that nanoparticles as a reinforcer causes the joint surface between two phases. As a result of swelling of the clay layers and strong adhesion between the polymer and the clay, the composite increases in strength [24]. Therefore, nanoparticles increase the tensile and flexural strength of WPC [25].

The coupling agent's percentage increases the joint strength between the two phases of cellulosic and polymer. In other words, the use of a coupling agent creates a more homogeneous structure in the composite. It causes a better stress distribution during the application of static load. Less stress concentration will occur in one area of the material, increasing stress-bearing capacity and flexural strength. To effectively transfer the stress and distribute the load correctly, it must have a strong connection at the two phases' joint surface. Without a coupling agent, nanofiller particles are present as separate components with weak bonds within the substrate. Therefore, they cannot participate effectively in the stress distribution [26,27].

Since the amount of wood particles added increases the modulus of elasticity in all three levels, and as lignocellulosic materials have a higher modulus of elasticity, so the value of Young's moduli of the composite material increases with the addition of wood flour to polyethylene [28]. The modulus increase indicates a decrease in the composite material's deformation under load, which is a positive factor in engineering structures that must withstand a large load without deformation [29]. Therefore, increasing the modulus of elasticity concerning the relationship $\mathrm{E}=\sigma / \varepsilon$ and decreasing the samples' strain by increasing the amount of wood flour can also be justified.

In WPC, with high numbers of fibers, the matrix has the role of adhesive for bonding wood particles to each other [30]. This leads to a mechanical bond between the wood and 
polymer particles. Lack of chemical bonding is due to plastic's non-polar nature and wood fibers' polar nature [31]. The volume of wood powder in the polyethylene leads to the polymer's cracking and reduces strain. On the other hand, with more wood flour, the strain values have been significantly reduced. Therefore, according to the relation $E \varepsilon=\sigma$, the value of the modulus of elasticity increased, causing a sharp decrease in the value of strain and reduced tensile strength.

Furthermore, the mechanical test was simulated using Abaqus software. The results indicate a difference between the failure force's values from the experimental test and numerical analysis. This difference may be due to the test sample's adjustment in the device's grips. This situation is minimized when closing the specimens, but it does not disappear completely. However, in software simulation, the problem is entirely ideal. Furthermore, in theory, and numerical simulation, the model is created as a continuous medium. In other words, the whole body is filled with material particles. In the experimental part, voids filled with oxygen may arise during the molding process, providing different results, such as fracture force. What is more, when the WPCs matrix exceeds its maximum capacity, cracks will appear. This effect will decrease the stiffness of the whole material and contribute to the difference between experimental and numerical results. More importantly, as we used fixtures to do the mechanical tests, some loss between jaws and the part existed. However, the part modeled in the FEM software is entirely fixed, and this discrepancy can result in some differences in the numerical results of experimental vis-à-vis FEM.

\section{Conclusions}

In summary, the mechanical properties of WPCs reinforced with the addition of nanoparticles are investigated. As reported in this manuscript, the inclusion of nanoclay particles has a significant effect on the material's physical and mechanical properties. The heterogeneity and high surface-to-volume ratio of nanoclay with organic matter contribute to nanoparticles' enhancement capability. It is done so that the nanoclay particles, as reinforcements, increase the surface area. On the other hand, with the addition of clay, the composite's strength increases due to swelling of clay layers and strong surface adhesion between the polymer and clay. For this reason, the results show that with increasing the amount of nanoclay and wood powder, the tensile and flexural strength of WPC has increased [32].

- Since nanoclay particles create stress areas and cracking points of failure, as nanoclay increases, the impact resistance of the composite decreases.

- The presence of nanoclay increases the energy absorbed by the composite, so increasing the amount of nanoclay creates areas in the polymer matrix that cause more stress, and cracking starts from that area [32].

- The results show that by increasing the amount of nanoclay, the impact resistance of the WPC specimens has decreased [33].

- The increase of Young's modulus and flexular modulus in the composite consisting of nanoclay depends directly on the average length of nanoclay particles and their dimensional ratio.

- The difference between the amount of shrinkage with increasing Young's modulus and flexular modulus of WPC has increased [34,35].

The results of mechanical tests showed that the amount of wood powder impacts Young's modulus.

- This phenomenon is due to lignocellulosic materials having higher Young's moduli than polymer. So the value of the modulus of elasticity of the composite material increases with the addition of wood flour to polyethylene [28,29].

- With the addition of wood powder, the strain values reduce. Accordingly, the relation $\sigma=E \varepsilon$, with the increased Young's moduli and decreased strain value reduction of tensile strength is obtained $[30,31]$. 
Author Contributions: Conceptualization, M.E.G. and S.M.M.; methodology, M.E.G.; software, S.M.M.; validation, M.E.G., S.M.M., T.W. and M.M.; formal analysis, M.E.G.; investigation, M.E.G. and S.M.M.; resources, M.E.G. and S.M.M.; data curation, M.E.G. and S.M.M.; writing-original draft preparation, T.W. and M.M.; writing-review and editing, T.W. and M.M.; visualization, T.W.; supervision, M.E.G. and V.A.E.; project administration, M.E.G. and V.A.E.; funding acquisition, S.M.M. All authors have read and agreed to the published version of the manuscript.

Funding: Open access funding provided by Gdansk University of Technology.

Institutional Review Board Statement: Not applicable.

Informed Consent Statement: Not applicable.

Data Availability Statement: Data available on request due to restrictions e.g., privacy or ethical. The data presented in this study are available on request from the corresponding author. The data are not publicly available due to privacy of results belonging to the Islamic Azad University.

Acknowledgments: The equipment which prepared the reported work was financially supplied by the fourth author (S.M.M.).

Conflicts of Interest: The authors declare no conflict of interest.

\section{References}

1. Joshi, S.; Drzal, L.; Mohanty, A.; Arora, S. Are Natural Fiber Composites Environmentally Superior to Glass Fiber Reinforced Composites? Compos. Part A Appl. Sci. Manuf. 2004, 35, 371-376. [CrossRef]

2. Feifel, S.; Stübs, O.; Seibert, K.; Hartl, J. Comparing Wood-Polymer Composites with Solid Wood: The Case of Sustainability of Terrace Flooring. Eur. J. Wood Wood Prod. 2015, 73, 829-836. [CrossRef]

3. Gardner, D.J.; Han, Y.; Wang, L. Wood-Plastic Composite Technology. Curr. For. Rep. 2015, 1, 139-150. [CrossRef]

4. Kim, J.K.; Pal, K. Recent Advances in the Processing of Wood-Plastic Composites; Engineering Materials; Springer: Berlin/Heidelberg, Germany, 2011; Volume 32, ISBN 978-3-642-14876-7.

5. Fabiyi, J.S.; McDonald, A.G.; McIlroy, D. Wood Modification Effects on Weathering of HDPE-Based Wood Plastic Composites. J. Polym. Environ. 2009, 17, 34-48. [CrossRef]

6. Fabiyi, J.S.; McDonald, A.G. Effect of Wood Species on Property and Weathering Performance of Wood Plastic Composites. Compos. Part A Appl. Sci. Manuf. 2010, 41, 1434-1440. [CrossRef]

7. Oksman, K. Mechanical Properties of Natural Fibre Mat Reinforced Thermoplastic. Appl. Compos. Mater. 2000, 7, 403-414. [CrossRef]

8. Fallis, A. Mechanical and Physical Properties of Wood-Plastic Composites Made of Polypropylene, Wood Flour and Nanoclay. J. Chem. Inf. Model. 2013, 53, 1689-1699.

9. Zini, E.; Scandola, M. Green Composites: An Overview. Polym. Compos. 2011, 32, 1905-1915. [CrossRef]

10. Ashori, A. Wood-Plastic Composites as Promising Green-Composites for Automotive Industries! Bioresour. Technol. 2008, 99, 4661-4667. [CrossRef]

11. Sauerbier, P.; Köhler, R.; Renner, G.; Militz, H. Plasma Treatment of Polypropylene-Based Wood-Plastic Composites (WPC): Influences of Working Gas. Polymers 2020, 12, 1933. [CrossRef]

12. Faruk, O.; Matuana, L. Nanoclay Reinforced HDPE as a Matrix for Wood-Plastic Composites. Compos. Sci. Technol. 2008, 68, 2073-2077. [CrossRef]

13. Kord, B.; Sheykholeslami, A.; Najafi, A. Effect of Nanoclay on the Flexural Creep Behavior of Wood/Plastic Composites. Mech. Compos. Mater. 2016, 51, 731-736. [CrossRef]

14. Ruijun, G.; Kokta, B.V.; Michalkova, D.; Dimzoski, B.; Fortelny, I.; Slouf, M.; Krulis, Z. Characteristics of Wood-Plastic Composites Reinforced with Organo-Nanoclays. J. Reinf. Plast. Compos. 2010, 29, 3566-3586. [CrossRef]

15. Sharma, B.; Mahajan, S.; Chhibber, R.; Mehta, R. Glass Fiber Reinforced Polymer-Clay Nanocomposites: Processing, Structure and Hygrothermal Effects on Mechanical Properties. Procedia Chem. 2012, 4, 39-46. [CrossRef]

16. Islam, M.E.; Mahdi, T.H.; Hosur, M.V.; Jeelani, S. Characterization of Carbon Fiber Reinforced Epoxy Composites Modified with Nanoclay and Carbon Nanotubes. Procedia Eng. 2015, 105, 821-828. [CrossRef]

17. Deepak, K.; Reddy, N.S.; Naidu, T.V.S. Thermosetting Polymer and Nano Clay Based Natural Fiber Bio- Composites. Procedia Mater. Sci. 2015, 10, 626-631. [CrossRef]

18. Zunjarrao, S.C.; Singh, R.P. Characterization of the Fracture Behavior of Epoxy Reinforced with Nanometer and Micrometer Sized Aluminum Particles. Compos. Sci. Technol. 2006, 66, 2296-2305. [CrossRef]

19. Srinivasa, C.V.; Bharath, K. Impact and Hardness Properties of Areca Fiber-Epoxy Reinforced Composites. J. Mater. Environ. Sci. 2011, 2, 351-356.

20. ASTM D638-02a. Standard Test Method for Tensile Properties of Plastics; ASTM: West Conshohocken, PA, USA, 2003.

21. ASTM D790-02. Flexural Properties of Unreinforced and Reinforced Plastics and Electrical Insulating Materials; ASTM: West Conshohocken, PA, USA, 2002. 
22. Zhao, Y.; Wang, K.; Zhu, F.; Xue, P.; Jia, M. Properties of Poly(Vinyl Chloride)/Wood Flour/Montmorillonite Composites: Effects of Coupling Agents and Layered Silicate. Polym. Degrad. Stab. 2006, 91, 2874-2883. [CrossRef]

23. Samal, S.K.; Nayak, S.K.; Mohanty, S. Polypropylene Nanocomposites: Effect of Organo-Modified Layered Silicates on Mechanical, Thermal \& Morphological Performance. J. Thermoplast. Compos. Mater. 2008, 21, 243-263. [CrossRef]

24. Wu, Q.; Lei, Y.; Yao, F.; Xu, Y.; Lian, K. Properties of HDPE/Clay/Wood Nanocomposites. In Proceedings of the First International Conference on Integration and Commercialization of Micro and Nanosystems, Parts A and B; ASMEDC, Sanya, China, 10-13 January 2007; pp. 181-188.

25. Asif, A.; Leena, K.; Lakshmana Rao, V.; Ninan, K.N. Hydroxyl Terminated Poly(Ether Ether Ketone) with Pendant Methyl Group-Toughened Epoxy Clay Ternary Nanocomposites: Preparation, Morphology, and Thermomechanical Properties. J. Appl. Polym. Sci. 2007, 106, 2936-2946. [CrossRef]

26. Rowell, R.M.; Lange, S.E.; Jacobson, R.E. Weathering Performance of Plant-Fiber/Thermoplastic Composites. Mol. Cryst. Liq. Cryst. Sci. Technol. Sect. A Mol. Cryst. Liq. Cryst. 2000, 353, 85-94. [CrossRef]

27. Qiang, Y.; Donglyang, W.; Gotama, J.; Bateman, S. Wood Fiber Reinforced Polyethylene and Polypropylene Composites with High Modulus and Impact Strength. J. Thermoplast. Compos. Mater. 2008, 21, 195-208. [CrossRef]

28. Jayaraman, K.; Bhattacharyya, D. Mechanical Performance of Woodfibre-Waste Plastic Composite Materials. Resour. Conserv. Recycl. 2004, 41, 307-319. [CrossRef]

29. Mostafazadeh Marzenaki, M.; Kazemi Najafi, S.; Chaharmahali, M.; Hajihasani, R. Study behavior creep composites made mixes particle board and medium density fiber board-recycled from hdpe waste and effect water fiber board absorption on composites. Iran. J. Wood Pap. Sci. Res. 2009, 24, 194-205.

30. Chaharmahali, M.; Tajvidi, M.; Najafi, S.K. Mechanical Properties of Wood Plastic Composite Panels Made from Waste Fiberboard and Particleboard. Polym. Compos. 2008, 29, 606-610. [CrossRef]

31. Mirmehdi, M.; Omidvar, A.; Madhoushi, M.; Shakeri, A. Investigation on the Mechanical Properties of Polyethylene/Date Palm Wood Flour Composite: The Effect of Filler Content and Type. Iran. Stud. 2011, 18, 77-92. (In Persian)

32. Chowdhury, F.H.; Hosur, M.V.; Jeelani, S. Studies on the Flexural and Thermomechanical Properties of Woven Carbon/NanoclayEpoxy Laminates. Mater. Sci. Eng. A 2006, 421, 298-306. [CrossRef]

33. Yang, Z.; Peng, H.; Wang, W.; Liu, T. Crystallization Behavior of Poly( $\varepsilon$-Caprolactone)/Layered Double Hydroxide Nanocomposites. J. Appl. Polym. Sci. 2010. [CrossRef]

34. Wang, L.; Wang, K.; Chen, L.; Zhang, Y.; He, C. Preparation, Morphology and Thermal/Mechanical Properties of Epoxy/Nanoclay Composite. Compos. Part. A Appl. Sci. Manuf. 2006, 37, 1890-1896. [CrossRef]

35. Han, G.; Lei, Y.; Wu, Q.; Kojima, Y.; Suzuki, S. Bamboo-Fiber Filled High Density Polyethylene Composites: Effect of Coupling Treatment and Nanoclay. J. Polym. Environ. 2008, 16, 123-130. [CrossRef] 